\title{
Induction of Granulysin and Perforin Cytolytic Mediator Expression in 10-Week-Old Infants Vaccinated with BCG at Birth
}

\author{
Patricia L. Semple, ${ }^{1}$ Marcia Watkins, ${ }^{1,2}$ Virginia Davids, ${ }^{3}$ Alan M. Krensky, ${ }^{4}$ \\ Willem A. Hanekom, ${ }^{3,5}$ Gilla Kaplan, ${ }^{6}$ and Stanley Ress ${ }^{1,7}$ \\ ${ }^{1}$ Division of Clinical Immunology, Department of Medicine, University of Cape Town, Cape Town 7925, South Africa \\ ${ }^{2}$ National Health Laboratory Service, Cape Town 8000, South Africa \\ ${ }^{3}$ South African Tuberculosis Vaccine Initiative, Institute of Infectious Diseases and Molecular Medicine, \\ University of Cape Town, Cape Town 7700, South Africa \\ ${ }^{4}$ National Cancer Institute, National Institutes of Health, Bethesda, MD 20892-8322, USA \\ ${ }^{5}$ School of Child and Adolescent Medicine, University of Cape Town, Cape Town, South Africa \\ ${ }^{6}$ Laboratory of Mycobacterial Immunity and Pathogenesis, Public Health Research Institute, \\ University of Medicine and Dentistry of New Jersey, Newark, NJ 07103-3535, USA \\ ${ }^{7}$ Groote Schuur Hospital, Cape Town 7925, South Africa
}

Correspondence should be addressed to Stanley Ress, stan.ress@uct.ac.za

Received 16 August 2010; Accepted 27 October 2010

Academic Editor: James Triccas

Copyright ( 2011 Patricia L. Semple et al. This is an open access article distributed under the Creative Commons Attribution License, which permits unrestricted use, distribution, and reproduction in any medium, provided the original work is properly cited.

\begin{abstract}
Background. While vaccination at birth with Mycobacterium bovis Bacilli Calmette-Guérin (BCG) protects against severe childhood tuberculosis, there is no consensus as to which components of the BCG-induced immune response mediate this protection. However, granulysin and perforin, found in the granules of cytotoxic T lymphocytes and Natural Killer (NK) cells, can kill intracellular mycobacteria and are implicated in protection against Mycobacterium tuberculosis. Methods. We compared the cellular expression of granulysin and perforin cytolytic molecules in cord blood and peripheral blood from 10-week-old infants vaccinated at birth with either Japanese or Danish BCG, administered either intradermally or percutaneously. Results. In cord blood, only CD56 $6^{+}$NK cells expressed granulysin and perforin constitutively. These cytolytic mediators were upregulated in CD $4^{+}$and CD $8^{+}$ cord blood cells by ex vivo stimulation with BCG but not with PPD. Following BCG vaccination of neonates, both BCG and PPD induced increased expression of granulysin and perforin by $\mathrm{CD}^{+}$and $\mathrm{CD} 8^{+} \mathrm{T}$ cells. There was no difference in expression of cytolytic molecules according to vaccination route or strain. Conclusions. Constitutive expression of perforin and granulysin by cord blood NK-cells likely provides innate immunity, while BCG vaccination-induced expression of these cytolytic mediators may contribute towards protection of the neonate against tuberculosis.
\end{abstract}

\section{Introduction}

It is estimated that approximately one third of the world's population is infected with Mycobacterium tuberculosis (M.tb) resulting in about 1.7 million deaths from tuberculosis (TB) annually [1]. Mycobacterium bovis Bacille Calmette Guérin (BCG) is the most commonly used vaccine worldwide and the only vaccine available for the prevention of TB. The vaccine offers good protection against childhood miliary disease and TB meningitis $[2,3]$ and has been associated with a reduced risk of acute respiratory tract infections in neonates [4]. However, BCG affords very little protection against pulmonary $\mathrm{TB}$ and other manifestations of adult disease. It has been suggested that the strain of BCG and the route of administration may affect the efficacy of the vaccine [5-8] as well as determine the nature of the antigenspecific T-cell responses [9].

Both innate and adaptive cellular immune responses are required for an effective host defense against M.tb and individuals with defective cell-mediated immunity (CMI) 
have a predisposition towards developing $\mathrm{TB}$, or towards more severe disease [10]. T-cell derived interferon gamma (IFN- $\gamma$ ) is widely recognized as important in antimicrobial protection. This cytokine is essential for the activation of macrophages, a process required to limit the replication of the bacilli in these cells $[11,12]$. However, despite having a full repertoire of helper and cytotoxic T-cells, Bcells, and dendritic cells (DC) [13], circulating neonatal lymphocytes are functionally distinct as compared with adults. Consequently, activation is submaximal [14] and IFN- $\gamma$ production in response to mycobacterial antigens is significantly lower in neonates $[15,16]$. However, the value of IFN- $\gamma$ as the best correlate of protection against TB has been challenged [17, 18]. Lymphoid cell-derived cytotoxic molecules found in cytotoxic lymphocytes (CTL) and natural killer (NK) cells have also been implicated in contributing to protective immunity against intracellular pathogens. These cells contain granules rich in granulysin, perforin and granzyme, molecules that contribute to lysis of infected cells. Granulysin, a member of the saponin-like family of lipid binding proteins, has also been shown to directly kill extracellular bacilli and, together with perforin, was able to substantially reduce the viability of intracellular M.tb [19].

The aim of our study was to evaluate the expression of granulysin and perforin in NK cells and T-cells in cord blood mononuclear cells (CBMCs) and to compare this with peripheral blood mononuclear cells (PBMCs) from neonates after vaccination with BCG. PBMCs from healthy adults who were purified protein derivative of tuberculin (PPD) responsive in vitro were used as controls. In addition, we determined whether the route and strain of BCG vaccination affected the expression of these cytolytic mediators. The results show that while T-cells from CBMCs do not express granulysin or perforin constitutively, BCG vaccination at birth results in strong upregulation of these mediators in the T-cells of 10-week-old infants. NK cells from CBMCs and PBMC of vaccinated infants constitutively expressed both markers. Variation in route and strain of BCG vaccine did not have a significant effect on cytotoxic mediator expression in T-cells or NK cells of PBMC obtained from 10-week-old neonates.

\section{Material and Methods}

2.1. Human Subjects and Vaccination. Healthy HIV-negative pregnant women scheduled to undergo elective Ceasarian section, due to previous Ceasarian sections, were recruited for umbilical cord blood (UCB) collection. This population was selected to avoid the effects of labour on immune responses.

Healthy 10-week-old infants were enrolled at primary care clinics in the Cape Town region. At birth, the babies had received either Japanese BCG (strain 172: Japan BCG Laboratory) or Danish BCG (strain 1331: Statens Serum Institute). The Japanese vaccine was administered either intradermally (JID) or percutaneously (JPC), while the Danish vaccine was given intradermally (DID). Infants with any acute or chronic disease, born to an HIV+ mothers, or living with a person with active tuberculosis, were excluded. A positive ELISA test for HIV, performed on all infants, also resulted in exclusion.

A positive proliferative response to PPD stimulation in peripheral blood (as defined by both microscopic cell clustering and flow cytometric evaluation) was used to identify healthy adults with prior exposure to mycobacterial antigens, and potentially latently infected with M.tb. All volunteers were HIV negative and were clinically well. Human participation was according to the US Department of Health and Human Services and Good Clinical Practice guidelines. This included the protocol approval by the University of Cape Town Research Ethics Committee and by the UMDNJ Institutional Review Board and informed written consent from a parent of the neonate or from the adult volunteers.

2.2. Cord Blood Mononuclear Cells (CBMCs). After inserting a needle with collection tubing into the umbilical vein of the placenta, the blood was allowed to flow by gravity into a standard blood donation bag (Sabax, Johannesburg, South Africa) containing 2000 units of sodium heparin (Sigma- Aldrich, Steinham, Germany). In the laboratory, the UCB was diluted with equal volumes of $\mathrm{Ca}^{+}$and $\mathrm{Mg}^{+}$free phosphate buffered saline (PBS, Bio Whittaker, Walkersville, MD, USA), and mononuclear cells were isolated by density sedimentation using Ficoll-Hypaque (SigmaAldrich, Steinham, Germany). Due to the large number of erythroid precursor cells in UCB, the procedure was repeated [20]. After the final wash the CBMCs were suspended in RPMI (Bio Whittkaker) supplemented with 10\% human AB serum (Western Province Blood Transfusion Service, South Africa).

2.3. BCG-Vaccinated Infant and PPD-Reactive Adult Peripheral Blood Mononuclear Cells (PBMCs). PBMC were separated as described for CBMCs, except that a single density gradient centrifugation was performed. PBMCs were cryopreserved until analysis: preliminary experiments showed no significant difference between cytolytic mediator expression in freshly isolated PBMCs and cryopreserved PBMCs from the same donors in both adults and 10-week-old infants (data not shown). Cell viability was determined by trypan blue exclusion dye (Sigma Aldrich).

2.4. Stimulation of CBMCs and PBMCs. $1 \times 10^{6} \mathrm{cells} / \mathrm{ml}$ were stimulated with $6 \mu \mathrm{g} / \mathrm{ml}$ of PPD (Statens Serum Institute, DM) or $100 \mathrm{IU}$ interleukin-2 (Aldesleukin, Chiron) for 7 days at $37^{\circ} \mathrm{C}$ in a $5 \% \mathrm{CO}_{2}$ humidified incubator. Unstimulated cells served as a background control. The duration of lymphoid cell stimulation was validated in preliminary experiments where granulysin and perforin expression was determined ex vivo and 1, 4, 6, 7, and 8/days after PPD and BCG stimulation. Although granulysin and perforin were detected in NK cells ex vivo, little or no expression was seen in $\mathrm{CD}^{+}{ }^{+}$and $\mathrm{CD}^{+}$T-cells until 4 days after stimulation and optimal expression peaked at day 7 (data not shown). 
CBMCs and PBMC isolated from adults who were PPDreactive were also stimulated with BCG (Danish BCG strain 1331, Statens Serum Institute) at a multiplicity of infection (MOI) of $1: 1$ and $5: 1$, respectively, shown to be optimal in preliminary experiments that evaluated cell death with the viability stain 7AAD. The 7-day duration of lymphoid cell stimulation was validated in preliminary experiments (data not shown).

2.5. Flow Cytometric Analysis. After stimulation with appropriate stimuli, the cells were washed with PBS containing 1\% human $\mathrm{AB}$ serum and $0.1 \%$ sodium azide (Sigma Aldrich), resuspended in the same medium (wash buffer) and counted on a haemacytometer. Cell viability was determined by trypan blue exclusion (Sigma Aldrich). Approximately 0.1 $\times 10^{6}$ viable cells were stained with CD3 FITC (Caltag, Burlingame, CA) or CD3 PerCP (BD Biosciences) and either CD4 APC or CD8 APC (Caltag) or CD56 APC (BD Biosciences) for 15 minutes at room temperature. After washing, the cells were fixed and permeabilised with FACS Permeabilising Solution (BD Biosciences) then stained with either rabbit polyclonal granulysin antibody (which specifically recognises the 9 and $15-\mathrm{kDa}$ forms of granulysin) [21-23] at a concentration of $1 / 1000$ or Perforin-FITC (BD Biosciences) for 30 minutes at $4^{\circ} \mathrm{C}$. For granulysin staining, $\mathrm{F}(\mathrm{ab})_{2}$ goat antirabbit $\operatorname{IgG}(\mathrm{H}+\mathrm{L})-\mathrm{PE}$ conjugated secondary antibody (Caltag) was added for 30 minutes at $4^{\circ} \mathrm{C}$. The cells were resuspended in the wash buffer for analysis on a FACSCalibur using Cell Quest software. Isotypic matched controls were used for all monoclonal antibodies while normal rabbit serum (Sigma Aldrich) served as a control for the granulysin polyclonal antibody. The flow cytometric gating strategy (shown in Figure 1(a)) was employed in order to define three distinct peripheral blood lymphocyte subsets for quantification of either granulysin or perforin expression. The lymphocyte gate was defined by forward and side scatter cell characteristics (R1). Within this population, $\mathrm{CD}^{+} \mathrm{T}$ cells were split into $\mathrm{CD} 3^{+} 4^{+}$or $\mathrm{CD}^{+} 8^{+}$subsets (i.e., cells that are in both gates $\mathrm{R} 1$ and $\mathrm{R} 2$ ), while $\mathrm{NK}$ cells were operationally defined as $\mathrm{CD}^{-} 56^{+}$(cells that are in both gates R1 and R3) (Figure 1).

2.6. Statistical Analysis. The primary outcomes were expression of granulysin or perforin in $\mathrm{CD}^{+}$or $\mathrm{CD}^{+} \mathrm{T}$ cells, or NK cells. These outcomes were compared according to mycobacterial infection status (naïve cord blood, BCGvaccinated infants, and healthy PPD-reactive adults) and according to antigen used in assays. The Mann-Whitney two-tailed test or Kruskal Wallis test was used to determine significance of differences, and results are stated throughout the text as medians with interquartile range. All statistical analysis was carried out using either GraphPad Instat (version 3.06) or GraphPad Prism software (version 4.0).

\section{Results}

3.1. Participants. Ten pregnant volunteers with a mean age of 26 years (range 19-34) consented to donating cord blood.
Ten PPD-reactive healthy adults $\left(\mathrm{PPD}^{+}\right)$with a mean age of 36 years (range 24-55) were enrolled in the study. The volunteers comprised of 5 males and 5 females. Forty five babies, vaccinated at birth with BCG, were enrolled in this study: 15 babies received DID whilst 31 babies were vaccinated with Japanese BCG: 15 with JID and 16 with JPC.

3.2. Effect of BCG Vaccination on PPD-Induced Granulysin Expression. CBMCs isolated from placental umbilical veins of 10 neonates were stimulated with PPD for 7 days. CD4 ${ }^{+}$ and $\mathrm{CD}^{+}$T-cells and $\mathrm{CD}^{+} 6^{+} \mathrm{NK}$ cells were analysed by flow cytometry for granulysin expression. IL-2 stimulated CBMCs acted as a positive control. Unstimulated and PPD stimulated cord blood CD4 ${ }^{+}$T-cells were either negative or expressed very low levels of granulysin (Figure 2(a)). Similar results were seen in cord blood $\mathrm{CD}^{+}$T-cells (Figure 2(b)). IL-2 stimulation of CBMCs in vitro induced an increase in the percentage of granulysin positive $\mathrm{CD}^{+} \mathrm{T}$ cells of $23.5 \%(12.5-62, P=.0001)$ and $\mathrm{CD}^{+} \mathrm{T}$ cells of $32.5 \%$ (10.5-55.5, $P=.0001)$. In contrast to T-cells, unstimulated NK cells expressed high levels of granulysin and the percentage of positive cells was decreased following PPD stimulation although this was not statistically significant $(P$ $=.09$, Figure $2(\mathrm{c}))$. Similarly, the level of granulysin in IL2 stimulated $\mathrm{CD}^{+} 6^{+}$cells was lower at 20.5\% (11.8-32.5), compared to the unstimulated cells at 52\% (34.7-59.8), and this was statistically significant $(P=.0025$, not shown).

When infants were vaccinated with BCG at birth and their PBMC evaluated for granulysin expression at 10 weeks postvaccination, a different pattern was seen. Granulysin was expressed in 2\% (0.5-3.5) of unstimulated $\mathrm{CD}^{+}$and $1 \%(1-2.5)$ of unstimulated $\mathrm{CD}^{+}$T-cells (Figures 2(a) and $2(\mathrm{~b}))$. After 7 days of in vitro PPD stimulation of PBMC, granulysin expression in both $\mathrm{CD}^{+}$and $\mathrm{CD}^{+} \mathrm{T}$ cells increased significantly to a median of $61 \%(46-76, P$ $\leq .0001)$ and $53 \%(9-72, P \leq .0001)$ of cells, respectively. IL-2 stimulation of PBMC induced similar strong expression with median of $34 \%(16.5-81, P \leq .0001)$ for $\mathrm{CD}^{+} \mathrm{T}$ cells and $69 \%(27.5-87, P \leq .0001)$ for $\mathrm{CD}^{+} \mathrm{T}$ cell (not shown). Thus, in contrast to CBMCs, PBMC of vaccinated babies had significantly higher levels of granulysin expressing $\mathrm{T}$ lymphocytes after in vitro PPD stimulation. This high level of expression is comparable to that previously obtained in adults [23]. Similar to CBMCs, constitutive expression of granulysin was seen in unstimulated NK cells of PBMC from vaccinated infants.

Healthy $\mathrm{PPD}^{+}$adult volunteer controls were also evaluated for granulysin expression in $\mathrm{NK}^{+}$cells, and $\mathrm{CD}^{+}$and $\mathrm{CD}^{+} \mathrm{T}$ cells. Unlike both the CBMCs and PBMC from the 10-week-old infants, constitutive granulysin expression was seen in $8 \%(5.5-22.5)$ of $\mathrm{CD}^{+}$T-cells (Figure 2). The median granulysin expression in PPD-stimulated adult PBMC was $39.5 \%(18-47.3)$ and $40.5 \%$ (28-48) for CD4 ${ }^{+}$ and $\mathrm{CD}^{+} \mathrm{T}$ cells, respectively, and 57\% (41.8-65.5) for NK cells. Compared to unstimulated cells, granulysin expression was significantly increased in PPD-stimulated $\mathrm{CD} 4^{+}$ $(P<.0001)$ and $\mathrm{CD}^{+} \quad(P=.0015)$ T-cells but there was no significant difference in granulysin expression between 


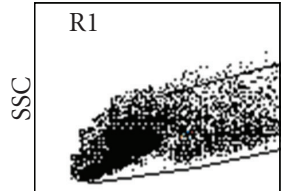

FSC

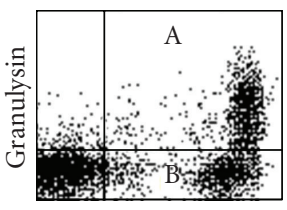

CD4 or CD8

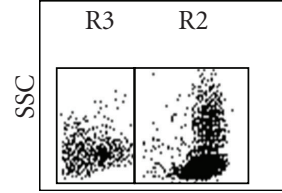

CD3

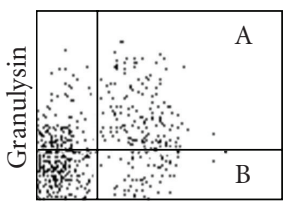

CD56

(a)
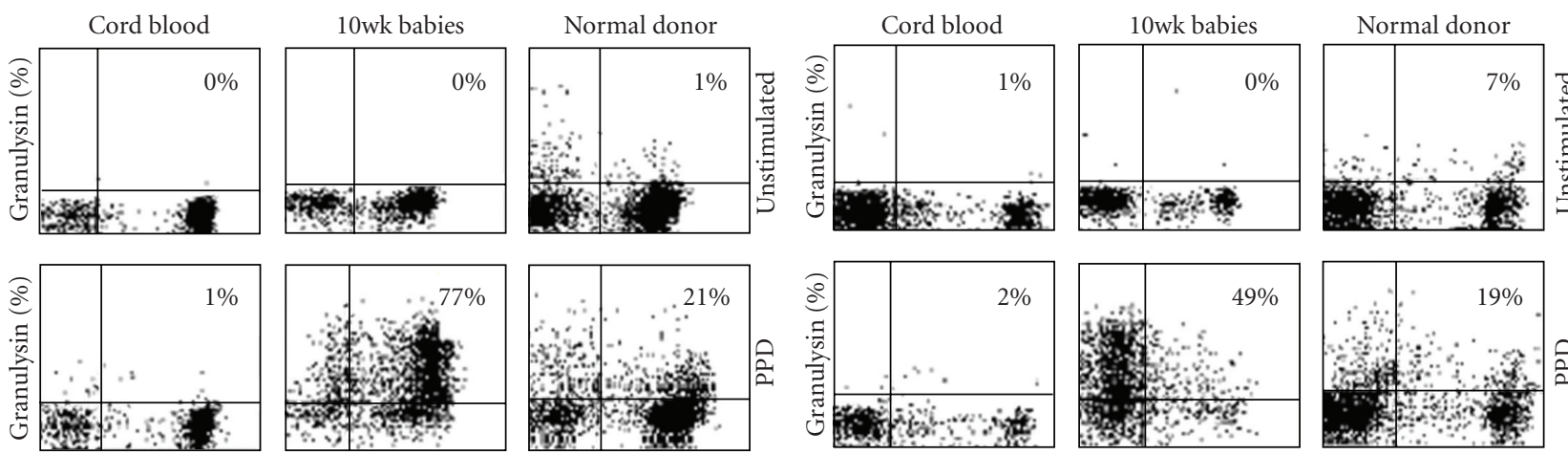

$\mathrm{CD}^{+}$

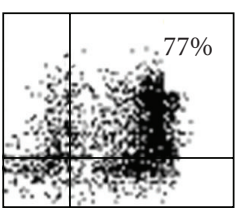

$\mathrm{CD}^{+}$

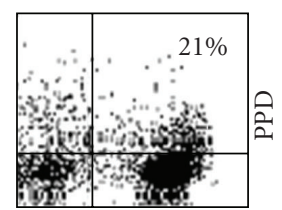

$\mathrm{CD} 4^{+}$

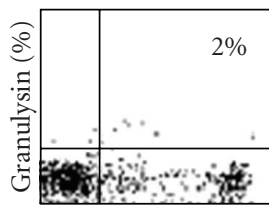

$\mathrm{CD}^{+}$

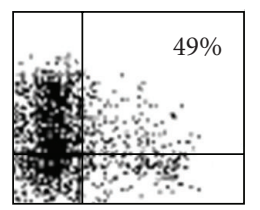

$\mathrm{CD}^{+}$

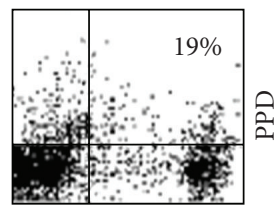

$\mathrm{CD}^{+}$
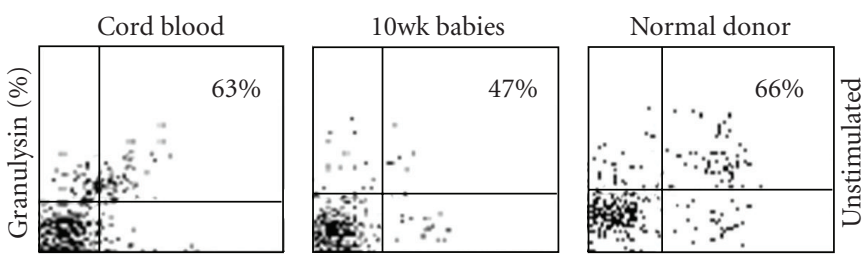

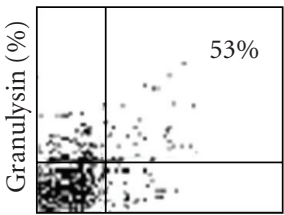

$\mathrm{CD}^{5} 6^{+}$

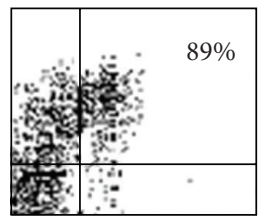

${\mathrm{CD} 56^{+}}^{+}$

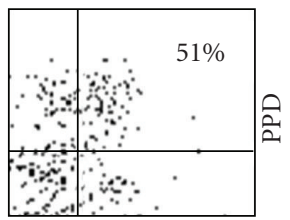

${\mathrm{CD} 56^{+}}^{+}$

(b)

FIGURE 1: (a) Flow cytometric diagram illustrating the gating strategy for the expression of granulysin (or Perforin) in T-cells and NK cells. R1 represents a general lymphocyte gate including all lymphocytes in a PPD stimulated PBMC sample. R2 incorporates all CD3 ${ }^{+}$T-cells within the R1 gate, and R3 includes all cells that are $\mathrm{CD}^{-}$. Percentage cells expressing granulysin (represented on the y-axis) are evaluated by dividing the number of cells in $\mathrm{A}$ by the number of cells in $\mathrm{A}+\mathrm{B} \times 100$. (b) Flow cytometric dotplots of granulysin in unstimulated or PPD-stimulated representative samples of cord blood mononuclear cells in the left column, 10-week-old infants after BCG vaccination in the middle column, and $\mathrm{PBMC}$ from healthy $\mathrm{PPD}^{+}$adult volunteers in the right column. Results shown represent T-lymphocytes which are $\mathrm{CD}^{+} / \mathrm{CD}^{+}$or $\mathrm{CD}^{+} / \mathrm{CD}^{+}$or NK cells which are $\mathrm{CD}^{+} 6^{+} / \mathrm{CD}^{-}$. See Section 2 for details.

unstimulated and PPD-stimulated NK cells $(P=.8)$. However, similar to CBMCs and PBMC from vaccinated babies, constitutive granulysin expression was also seen in $54.5 \%$ (34.8-73) of unstimulated CD56 ${ }^{+}$cells from healthy PPD+ adult controls.
3.3. Effect of BCG Vaccination on PPD-Induced Perforin Expression. A similar analysis was undertaken to determine levels of expression of perforin. Neither unstimulated CD4 ${ }^{+}$ nor $\mathrm{CD}^{+}$T-cells from cord blood, nor unstimulated $\mathrm{CD}^{+}{ }^{+}$or $\mathrm{CD}^{+} \mathrm{T}$ cells from 10 -week-old vaccinated infants 
$\mathrm{CD} 4^{+} \mathrm{T}$-cells expressing granulysin

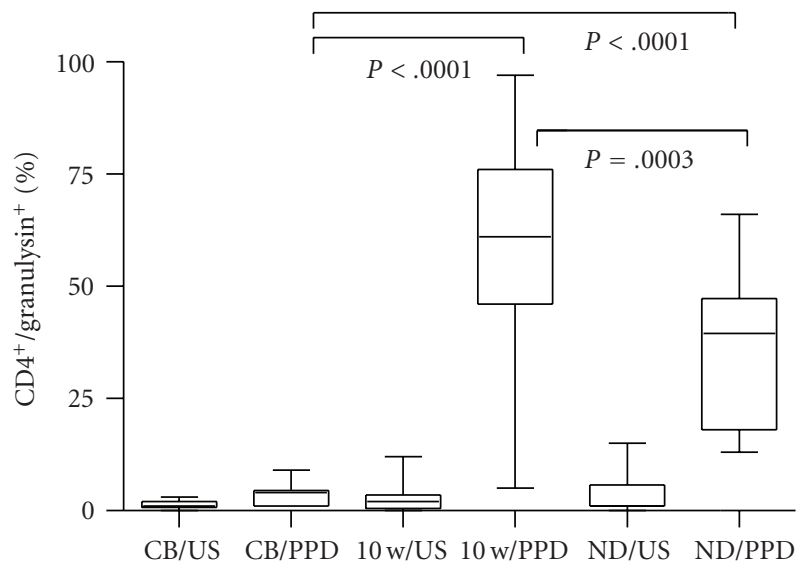

(a)

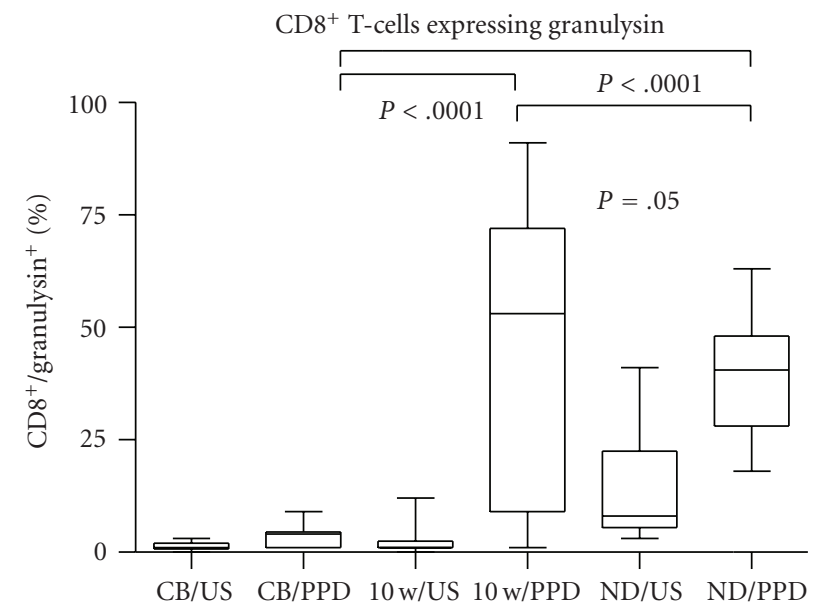

(b)
CD56 ${ }^{+}$NK cells expressing granulysin

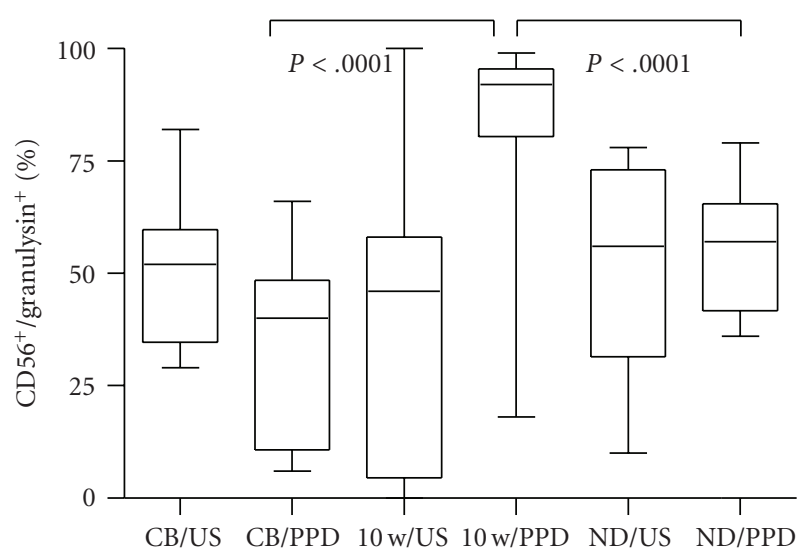

(c)

FIgURE 2: Granulysin expression in $\mathrm{CD}^{+}$(a) and $\mathrm{CD}^{+}$(b) T-cells and CD56 ${ }^{+}$(c) NK cells in unstimulated (US) and PPD-stimulated mononuclear cells isolated from cord blood $(\mathrm{CB}, n=10)$ or peripheral blood from BCG-vaccinated infants $(10 \mathrm{w}, n=45)$ or healthy PPD ${ }^{+}$ adult volunteers (ND, $n=10$ ). Significance is shown as PPD stimulation in CB compared to 10-week-old infants and healthy adult controls, and 10-week-old infants compared to healthy adult controls. The box extends from the 25th to 75th percentile, the line represents the median, and the whiskers represent the maximum and minimum values.

expressed perforin (Figures $3(\mathrm{a})$ and $3(\mathrm{~b}))$. In contrast, $38 \%$ (17-61.8) of NK-cells in CBMCs and 6\% (0-48.3) of NK cells in 10-week-old infant PBMC constitutively expressed the cytolytic marker (Figure 3(c)). Again, PPD stimulation did not induce expression of perforin in $\mathrm{CD}_{4}^{+}$or $\mathrm{CD} 8^{+} \mathrm{T}$-cells from cord blood (Figures 3(a) and 3(b)) while a reduction in the levels of expression in CD56 ${ }^{+} \mathrm{NK}$ cells to $16.5 \%$ (8-33.2, $P=.02$ ) as compared to unstimulated CBMCs was noted. In contrast, PPD stimulation induced significantly increased expression of perforin in PBMC of vaccinated infants both in CD4 ${ }^{+}$T-cells $(P=.04)$ and CD8 ${ }^{+}$T-cells $(P=.009)(27 \%$ $(13.8-44.3)$ and $38.5 \%(19.5-52.8)$, resp.) as well as in NK cells $(P<.0001)(87.5 \%(66-95))$. Compared to CBMCs, there was a significant difference in perforin expression after PPD stimulation in the 10 -week-old vaccinated infants in CD4 and CD8 T-cells ( $P, 0.0001$ for both T-cells, Figures 2(a) and 2(b)) and in NK cells $(P=.0003$, Figure 3(c)). After IL-2 stimulation, $18 \%(14-28.5, P=.0015)$ of $\mathrm{CD}^{+}$T-cells and $36 \%(22-40, P=.002)$ of $\mathrm{CD}^{+}$T-cells expressed perforin (not shown).

In $\mathrm{PPD}^{+}$adults, constitutive expression of perforin was seen in 3.5\% (2-11.8) of CD8 ${ }^{+}$T-cells and 76.5\% (57.585.8) of NK cells; after PPD stimulation, $14.5 \%$ (8.8-16.8) of CD4 ${ }^{+}$T-cells and $21 \%(17.3-25.3)$ of $\mathrm{CD}^{+} \mathrm{T}$-cells expressed perforin. PPD stimulation of NK cells resulted in a reduction of perforin expression (from $76.5 \%$ to $60 \%$ ).

3.4. Effect of BCG Stimulation on Granulysin and Perforin Expression in $\mathrm{CD}^{+}$and $\mathrm{CD} 8^{+} \mathrm{T}$ Cells of $\mathrm{CBMCs}$ and in $P B M C$ of $P P D^{+}$Healthy Adults. PBMC from healthy $\mathrm{PPD}^{+}$ adults and CBMCs were stimulated with Danish BCG, and granulysin and perforin expression was determined within 


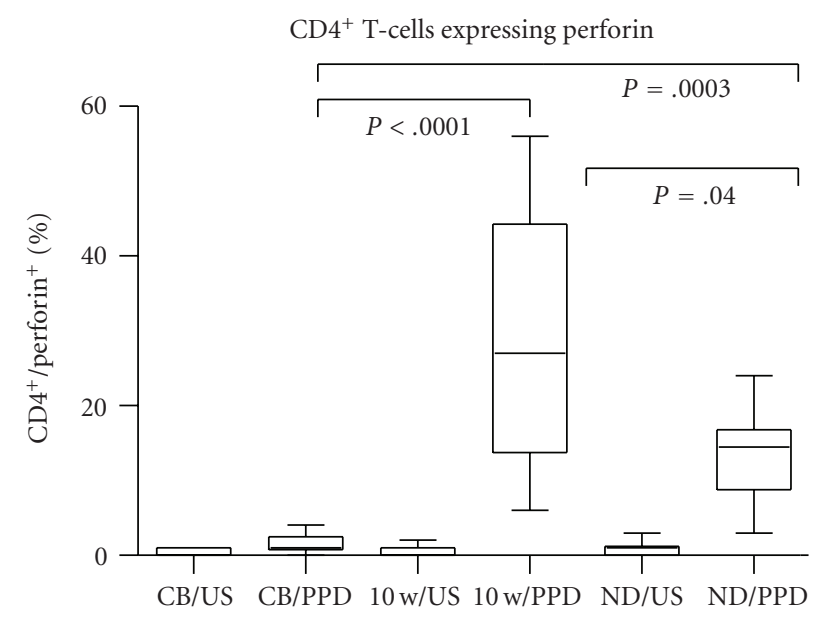

(a)

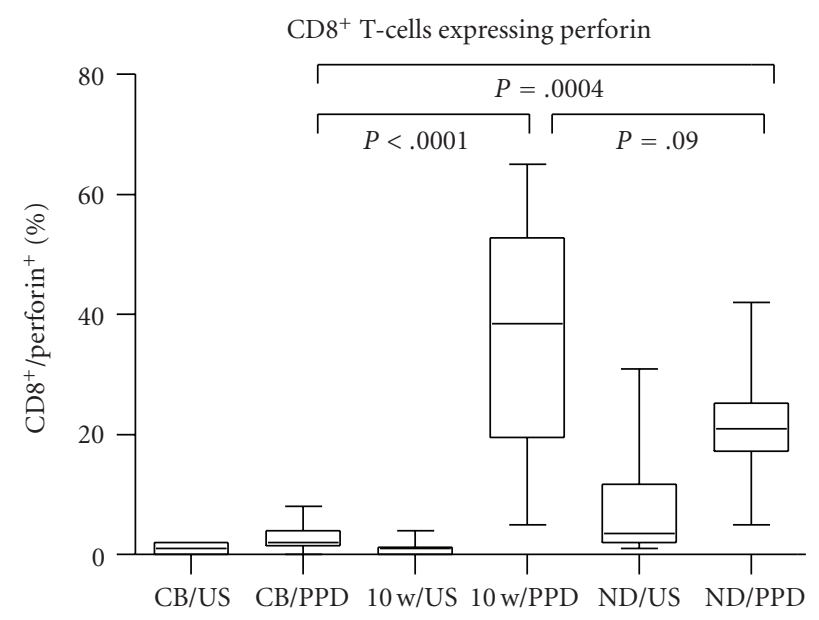

(b)

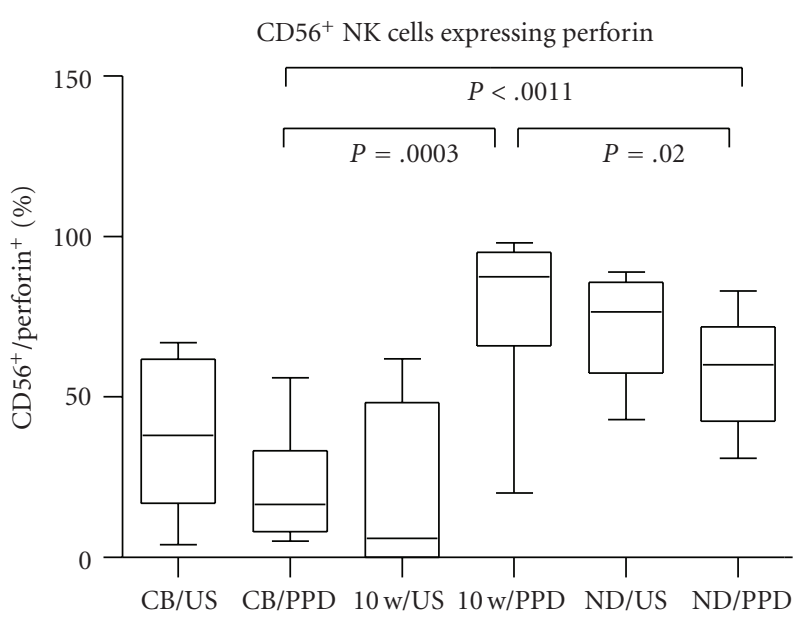

(c)

Figure 3: Perforin expression in $\mathrm{CD}^{+}$(a) and $\mathrm{CD}^{+}$(b) T-cells and CD56 ${ }^{+}$(c) NK cells in unstimulated (US) and PPD-stimulated mononuclear cells isolated from cord blood $(\mathrm{CB}, n=10)$ or peripheral blood from BCG-vaccinated infants $(10 \mathrm{w}, n=45)$ or healthy PPD ${ }^{+}$ adult volunteers (ND, $n=10$ ). Significance is shown as PPD stimulation in CB compared to 10 -week-old infants and healthy adult controls, and 10-week-old compared to healthy adult controls. The box extends from the 25th to 75th percentile, the line represents the median, and the whiskers represent the maximum and minimum values.

the respective $\mathrm{CD}^{+}$cells. Unlike PPD, BCG stimulation did result in an increase in both granulysin and perforin expressions in CBMCs. There was a statistically significant difference in granulysin expression in BCG-stimulated Tcells compared to PPD-stimulated T-cells $(P \leq 0.0001$ for $\mathrm{CD}^{+}$and $P=.0005$ for $\mathrm{CD}^{+}$, Figures $4(\mathrm{a})$ and $4(\mathrm{c})$ ) in CBMCs. Similarly, perforin-expressing T-cells were also increased in BCG-stimulated compared to PPD-stimulated CBMCs $\left(P=.003\right.$ for $\mathrm{CD}^{+}$and $P=.004$ for $\mathrm{CD}^{+}$, Figures 4(b) and 4(d)). 10.5\% (4-25) of $\mathrm{CD}^{+}$T-cells and $11 \%$ (6-27) of CD8 ${ }^{+}$T-cells expressed granulysin after BCG stimulation (Figure 4), and perforin expression was seen in $5.5 \%(2.5-17)$ and $8 \%(3.8-19)$ of $\mathrm{CD}^{+}$and $\mathrm{CD}^{+} \mathrm{T}$ cells, respectively, after BCG stimulation. Thus, although the percentage of expression was considerably lower than in healthy PPD positive adults, significant expression was induced in both lymphocyte subsets compared to PPD stimulation. In contrast, in $\mathrm{PPD}^{+}$healthy adult T-cells, equally strong granulysin and perforin expression was obtained with no significant difference between PPD and BCG stimulation being noted (Figures $4(\mathrm{a})-4(\mathrm{~d})$ ).

3.5. Effect of Route and Strain of the BCG Vaccine on Granulysin and Perforin in T-Cells and NK Cells of PBMCs from 10Week-Old Infants. To evaluate whether the strain of BCG or the route of administration of the vaccine affected the extent of cytotoxic molecule expression, PBMC from 10-week-old infants vaccinated with either Danish BCG administered intradermally ( $n=14$ granulysin and $n=3$ for perforin) or Japanese BCG administered either intradermally ( $n=15$ for granulysin and $n=4$ for perforin) or percutaneously ( $n=$ 16 granulysin, and $n=7$ for perforin) were evaluated for granulysin and perforin expression. Although the number of patients evaluated for perforin expression was low, no significant differences were found in granulysin or perforin expression between vaccination with Japanese or Danish 
$\mathrm{CD} 4^{+} \mathrm{T}$-cells expressing granulysin in unstimulated or PPD-or BCG-stimulated cells

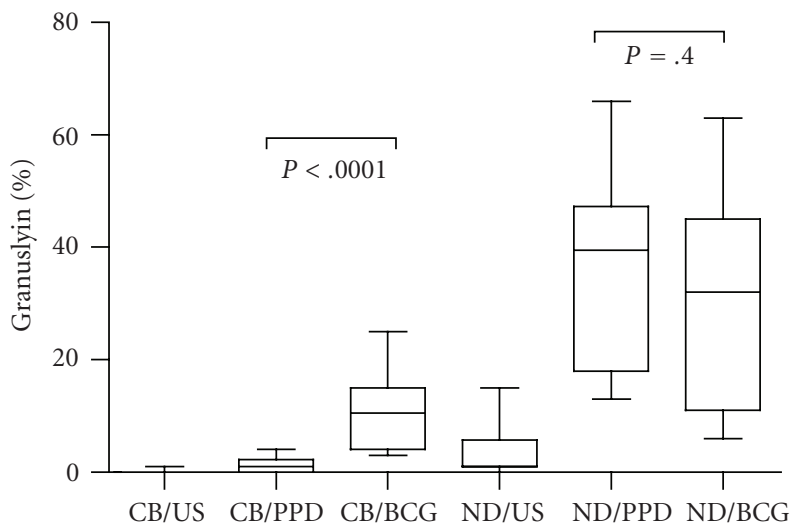

(a)

$\mathrm{CD}^{+} \mathrm{T}$-cells expressing granulysin in unstimulated or PPD-or BCG-stimulated cells

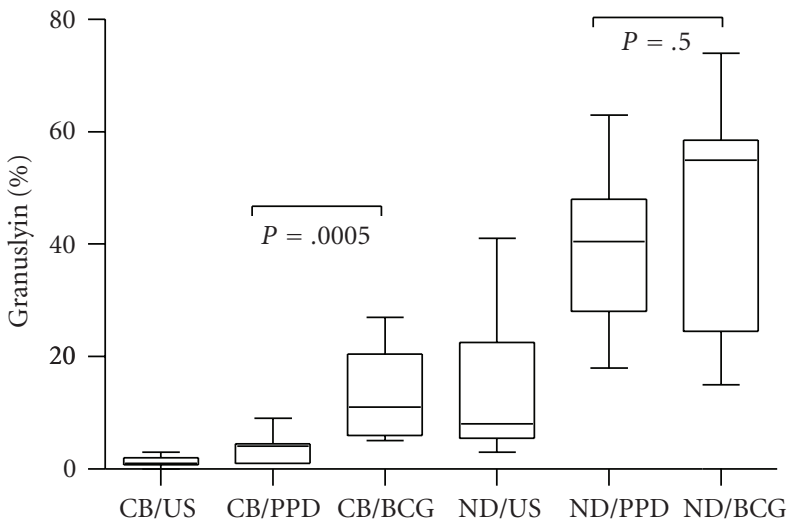

(c)
$\mathrm{CD} 4^{+} \mathrm{T}$-cells expressing perforin in unstimulated or PPD-or BCG-stimulated cells

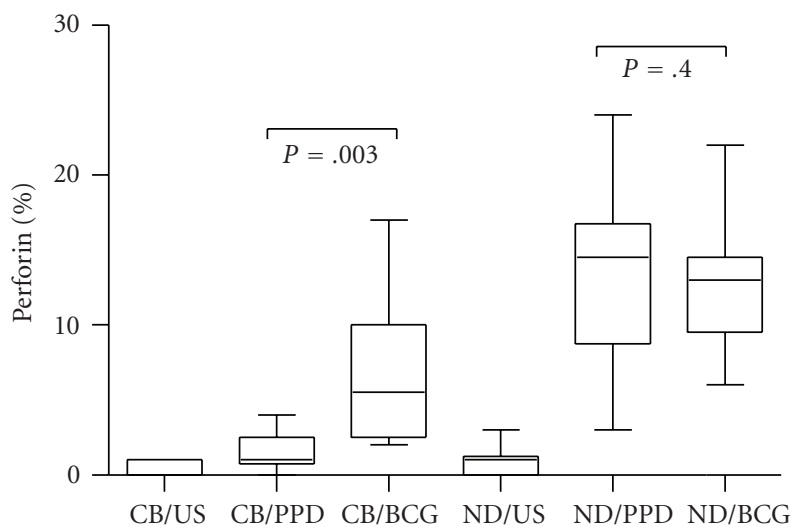

(b)

$\mathrm{CD} 8^{+} \mathrm{T}$-cells expressing perforin in unstimulated or PPD-or BCG-stimulated cells

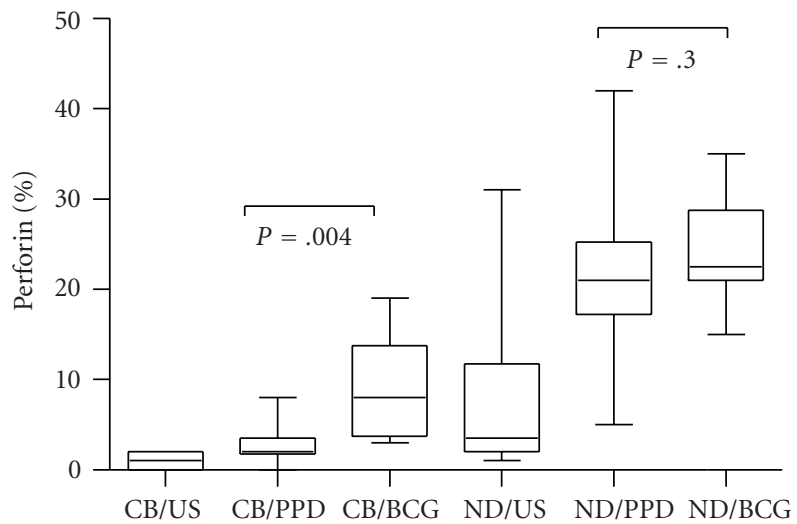

(d)

Figure 4: Percentage CD4 $3^{+}, \mathrm{CD}^{+} 3^{+}$expressing Granulysin (a, c), or Perforin (b, d) in unstimulated (US) or PPD- or BCG-stimulated cord blood mononuclear cells (CB $n=10)$ or peripheral blood mononuclear cells from healthy $\mathrm{PPD}^{+}$adult volunteers (ND $\left.n=10\right)$. Significance is shown between PPD and BCG stimulation in CB and adult volunteers. The box extends from the 25th to 75th percentile, the line represents the median, and the whiskers represent the maximum and minimum values.

BCG. Similarly, the route of administration of the vaccine also did not have any effect on expression of these markers (data not shown).

\section{Discussion}

In the current study, we have evaluated expression of the cytolytic mediators perforin and granulysin in both $\mathrm{CD}^{+} 6^{+} \mathrm{NK}$ cells and in $\mathrm{CD}^{+}$and $\mathrm{CD}^{+}$T-cell subsets in CBMCs and observed that (i) intrinsic expression of cytolytic mediators was limited to $\mathrm{CD} 56^{+}$cells and not found in $\mathrm{CD}^{+}$and $\mathrm{CD} 8^{+} \mathrm{T}$-cells and (ii) induction of perforin and granulysin expression in cord blood T-cells occurred selectively in response to in vitro stimulation with BCG, but not PPD. In contrast, in 10-week-old BCG-vaccinated infants, upregulation of perforin and granulysin expression in $\mathrm{CD}^{+}$and $\mathrm{CD}^{+}$T-cell was demonstrable in response to both BCG and PPD stimulation (data not shown). In this study, the response was independent of variation in vaccine strain or route of vaccine delivery (data not shown), although the sample size was small and not statistically powered. To our knowledge, a comprehensive comparative evaluation of $\mathrm{NK}$ and $\mathrm{CD} 4^{+}$and $\mathrm{CD} 8^{+} \mathrm{T}$ subset cytolytic mediator expression in cord blood and in BCG vaccinated infants has not been documented before. Previous studies have reported that cord blood $\mathrm{CD}^{+}{ }^{+}$lymphocytes lack constitutive expression of perforin [24] while most $\mathrm{CD} 8^{+} \mathrm{T}$ cells of newborns have been shown to contain perforin and granzyme. In contrast, we observed that unstimulated cord blood $\mathrm{CD} 8^{+} \mathrm{T}$-cells did not express granulysin or perforin. This difference may be explained by the fact that in our 
study the CBMCs were from mothers undergoing caesarean section. During normal vaginal delivery, cytokines including IL-15 may be induced which could activate $\mathrm{CD} 8^{+} \mathrm{T}$ cells to acquire cytotoxic potential [25].

Considerable evidence supports the observation that cytotoxic T-cell activation occurs during induction of the host protective immune response to TB [26-28]. We have previously documented $\mathrm{CD}^{+}$cytotoxic activity in BCGvaccinated neonates using a chromium release assay [29]. It has previously been shown that the level of expression of cytotoxic mediators is directly related to functional cytotoxic activity of memory $\mathrm{CD} 8^{+} \mathrm{T}$-cells [30]. Using this approach, we have reported on $\mathrm{CD}^{+}$cytotoxic molecule expression in infants who had received BCG vaccination at birth [31]. Here we demonstrate that cytotoxic cells expressing granulysin and perforin constitutively exist in neonatal blood even before BCG vaccination. Perforin and granulysin are important cytolytic effector molecules involved in lysis of infected macrophages. Granulysin, found in the granules of cytotoxic T-lymphocytes and NK cells, has a broad spectrum of antimicrobial activity [19]. The molecule has been shown to kill extracellular $M$. tuberculosis and, together with perforin, is bactericidal to intracellular organisms [19]. In addition, granulysin and perforin were significantly increased in lymphoid cells of cattle following vaccination with $M$. bovis BCG and $M$. bovis $\triangle \mathrm{RD} 1$ compared with nonvaccinated animals [32].

IFN- $\gamma$ production by CBMC NK cells is most needed after birth $[33,34]$, at a time when $\mathrm{CD}^{+} \mathrm{CD} 45 \mathrm{RO}-\mathrm{T}$ cells have down-regulated Th1 function by transcriptional regulation of the IFN- $\gamma$ promoter gene due to hypermethylation [35]. Intrinsic cytolytic mediator expression provides a second mechanism for NK cell mediated protective immunity during this critical period of heightened susceptibility to mycobacterial infection. Our observation that BCG upregulates cytotoxic molecules in cord blood $\mathrm{CD}^{+}$and $\mathrm{CD} 8^{+}$T-cells may also be secondary to activation of cells of the innate immune system. Since IL-2 treatment of the T-cells of cord blood directly upregulated perforin and granulysin expression, the effect of BCG could be via activation of NK cells to produce IL-2 which in turn could affect $\mathrm{CD} 4^{+}$and $\mathrm{CD} 8^{+} \mathrm{T}$-cell activation. Support for a central role of NK cells in the host response against TB infection also comes from the bovine model where activated NK cells were shown to have increased granulysin and perforin expression and to lyse Mycobacterium bovis BCG-infected alveolar and monocyte-derived macrophages [36].

The role of IFN- $\gamma$ producing $\mathrm{CD} 4^{+} \mathrm{T}$-cells in protection against TB is well described [37-39]. Support for a role for cytotoxic $\mathrm{CD}^{+}$effectors in protective immunity against $\mathrm{TB}$ comes from studies carried out in BCG-vaccinated cattle. In the bovine model, memory $\mathrm{CD}^{+}{ }^{+} \mathrm{T}$-cells expressing elevated levels of perforin and granulysin strongly lysed BCG-infected macrophages [40]. Cytotoxic CD4 ${ }^{+} \mathrm{T}$-cells have also been shown to use granulysin to kill Cryptococcus neoformans [41]. Furthermore, cytotoxic granulysin-expressing $\mathrm{CD} 4^{+} \mathrm{T}-$ cells have been isolated from skin lesions of tuberculoid leprosy patients [42]. Recently, Murray et al. showed that BCG vaccination induced specific $\mathrm{CD} 8^{+} \mathrm{T}$-cells which produced
IFN- $\gamma$ and had increased expression of cytotoxic proteins in response to BCG stimulation in vitro, providing evidence of a role for $\mathrm{CD}^{+}{ }^{+}$-cells as well [31]. This is supported by the finding of reduced perforin and granulysin coexpression in $\mathrm{CD}^{+}{ }^{-}$-cells found at the site of infection in chronic TB [43].

In the present study, we observed that there was no statistical difference in granulysin or perforin expression in cells obtained from neonates vaccinated at birth with either JID or DID and no difference between vaccinations via the two routes (intradermal versus percutaneous) of administration of the Japanese BCG. Differences have been reported in a study using a similar but larger cohort of infants, where JPC induced significantly more BCG-specific IFN- $\gamma$ producing $\mathrm{CD}^{+}$and $\mathrm{CD}^{+}{ }^{+}$T-cells and greater Th1specific immunity than JID or DID [9]. In addition, JPC induced greater $\mathrm{CD} 4^{+}$and $\mathrm{CD} 8^{+}$T-cell proliferation. Taken together, the data suggest that distinct factors are involved in promoting the development of the two pathways, that is, Th1 cytokine and T-cell proliferation and expansion of cytotoxic cells expressing granulysin and perforin. In support of this dichotomy, it has been shown that BCG-infected immature DCs selectively expanded perforin-positive CD8 ${ }^{+}$ T-cells with little contribution from cytokines, including IFN- $\gamma$, TNF- $\alpha$, or IL-12 [44]. In contrast, IL-15 promotes granulysin expression $[36,45]$ while IL-21 has been shown to enhance lytic activity of cytotoxic T-cells and NK cells [46]. These findings may have implications for immunotherapeutic boosting of cytotoxic $\mathrm{CD}^{+}$activity in $\mathrm{TB}$ and BCG vaccination protocols. In addition to therapeutic strategies aimed at inhibition of IL-4 and TGF $\beta$ [47], molecular engineering of BCG to incorporate IL-15 or IL-21 could result in enhanced cytotoxic activity of both NK cells and $\mathrm{CD} 8^{+}$cytotoxic T-cells.

In conclusion, data presented here demonstrate (i) constitutive expression of granulysin and perforin cytolytic mediators in NK cells which could provide innate protective immunity for newborn infants and (ii) that BCG vaccination at birth can induce a cytolytic effector function in neonates, where $\mathrm{CD}^{+}$and $\mathrm{CD} 8^{+}$T-cells are all essentially naïve. By contrast, PPD antigenic stimulation could only induce cytolytic effector functions in memory $\mathrm{CD}^{+}$and $\mathrm{CD} 8^{+}$ T-cells. While no currently available immunologic test can predict vaccine efficacy, BCG readily elicits a type 1 cytokine response $[29,48]$ and it has been proposed that additional factors may be important for vaccine efficacy. These include IL- 4 and the Th1 cytokine balance $[49,50]$ and induction of cytolytic activity in memory T-cells [40, 51]. Further research is needed to establish if BCG-induced cytolytic mediator expression is sustained in memory CTL. It has been postulated that protection due to BCG vaccination wanes with time [52] which may be due to overattenuation of BCG strains with resultant gene deletions [53] and failure to stimulate a durable immune response.

\section{Conflict of Interests}

A. M. Krensky holds patents on granulysin as follows: US6485928 Use of granulysin as an antimicrobial agent, US11438563 Antimicrobial peptides, and US4994369 T cell 
activation related gene (granulysin). P. L. Semple, M. L. V. Watkins, V. Davids, W. A. Hanekom, G. Kaplan, and S. R. Ress have no conflict of interests.

\section{Acknowledgments}

S. Ress was supported by a grant from the Medical Research Council Tuberculosis Vaccine Initiative. P. L. Semple was supported by National Research Foundation (Thuthuka). G. Kaplan and W. A. Hanekom were supported by the AERAS Global Tuberculosis Vaccine Foundation.

\section{References}

[1] WHO, Global Atlas of Infectious Diseases, World Health Organisation, Geneva, Switzerland, 2007.

[2] G. A. Colditz, C. S. Berkey, F. Mosteller et al., "The efficacy of bacillus Calmette-Guerin vaccination of newborns and infants in the prevention of tuberculosis: meta-analyses of the published literature," Pediatrics, vol. 96, no. 1, pp. 29-35, 1995.

[3] P. Fine, L. Reichman, and E. S. Hirschfield, "BCG vaccines and vaccination," in Tuberculosis, 2007.

[4] L. G. Stensballe, E. Nante, I. P. Jensen et al., "Acute lower respiratory tract infections and respiratory syncytial virus in infants in Guinea-Bissau: a beneficial effect of BCG vaccination for girls: community based case-control study," Vaccine, vol. 23, no. 10, pp. 1251-1257, 2005.

[5] N. Al Jarad, D. W. Empey, and G. Duckworth, "Administration of the BCG vaccination using the multipuncture method in schoolchildren: a comparison with the intradermal method," Thorax, vol. 54, no. 9, pp. 762-764, 1999.

[6] P. D. Hart, "Efficacy and applicability of mass B. C.G. vaccination in tuberculosis control," British Medical Journal, vol. 1, no. 540, pp. 587-592, 1967.

[7] E. B. Kemp, R. B. Belshe, and D. F. Hoft, "Immune responses stimulated by percutaneous and intradermal bacille CalmetteGuerin," Journal of Infectious Diseases, vol. 174, no. 1, pp. 113$119,1996$.

[8] L. P. Ormerod and C. Palmer, "Tuberculin reactivity after neonatal percutaneous BCG immunisation," Archives of Disease in Childhood, vol. 69, no. 1, p. 155, 1993.

[9] V. Davids, W. A. Hanekom, N. Mansoor et al., "The effect of bacille Calmette-Guérin vaccine strain and route of administration on induced immune responses in vaccinated infants," Journal of Infectious Diseases, vol. 193, no. 4, pp. 531-536, 2006.

[10] M. Khanna, L. M. Srivastava, and P. Kumar, "Defective interleukin-2 production and interleukin-2 receptor expression in pulmonary tuberculosis," Journal of Communicable Diseases, vol. 35, no. 2, pp. 65-70, 2003.

[11] S. H. E. Kaufmann and P. Andersen, "Immunity to mycobacteria with emphasis on tuberculosis: implications for rational design of an effective tuberculosis vaccine," Chemical Immunology, vol. 70, pp. 21-59, 1998.

[12] S. Stenger and R. L. Modlin, "T cell mediated immunity to Mycobacterium tuberculosis," Current Opinion in Microbiology, vol. 2, no. 1, pp. 89-93, 1999.

[13] B. Adkins, C. Leclerc, and S. Marshall-Clarke, "Neonatal adaptive immunity comes of age," Nature Reviews Immunology, vol. 4, no. 7, pp. 553-564, 2004.

[14] D. T. Harris, M. J. Schumacher, J. Locascio et al., "Phenotypic and functional immaturity of human umbilical cord blood $\mathrm{T}$ lymphocytes," Proceedings of the National Academy of Sciences of the United States of America, vol. 89, no. 21, pp. 1000610010, 1992.

[15] Y. Suen, S. M. Lee, J. Qian, C. Van De Ven, and M. S. Cairo, "Dysregulation of lymphokine production in the neonate and its impact on neonatal cell mediated immunity," Vaccine, vol. 16, no. 14-15, pp. 1369-1377, 1998.

[16] H. N. Trivedi, K. T. Hayglass, V. Gangur, J. G. Allardice, J. E. Embree, and F. A. Plummer, "Analysis of neonatal T cell and antigen presenting cell functions," Human Immunology, vol. 57, no. 2, pp. 69-79, 1997.

[17] D. Elias, H. Akuffo, and S. Britton, "PPD induced in vitro interferon gamma production is not a reliable correlate of protection against Mycobacterium tuberculosis," Transactions of the Royal Society of Tropical Medicine and Hygiene, vol. 99, no. 5, pp. 363-368, 2005.

[18] H.-W. Mittrücker, U. Steinhoff, A. Köhler et al., "Poor correlation between BCG vaccination-induced $\mathrm{T}$ cell responses and protection against tuberculosis," Proceedings of the National Academy of Sciences of the United States of America, vol. 104, no. 30, pp. 12434-12439, 2007.

[19] S. Stenger, D. A. Hanson, R. Teitelbaum et al., "An antimicrobial activity of cytolytic T cells mediated by granulysin," Science, vol. 282, no. 5386, pp. 121-125, 1998.

[20] J. Ridings, H. Weedon, C. Ioannou, L. Flego, P. J. Macardle, and H. Zola, "Purification of cord blood lymphocytes," Journal of Immunological Methods, vol. 195, no. 1-2, pp. 43-48, 1996.

[21] S. V. Peña, D. A. Hanson, B. A. Carr, T. J. Goralski, and A. M. Krensky, "Processing, subcellular localization, and function of 519 (granulysin), a human late T cell activation molecule with homology to small, lytic, granule proteins," Journal of Immunology, vol. 158, no. 6, pp. 2680-2688, 1997.

[22] J. L. Gansert, V. Kießler, M. Engele et al., "Human NKT cells express granulysin and exhibit antimycobacterial activity," Journal of Immunology, vol. 170, no. 6, pp. 3154-3161, 2003.

[23] D. H. Canaday, R. J. Wilkinson, Q. Li, C. V. Harding, R. F. Silver, and W. H. Boom, "CD4 ${ }^{+}$and $\mathrm{CD}^{+}{ }^{+} \mathrm{T}$ cells kill intracellular Mycobacterium tuberculosis by a perforin and Fas/Fas ligand-independent mechanism," Journal of Immunology, vol. 167, no. 5, pp. 2734-2742, 2001.

[24] C. Berthou, S. Legros-Maida, A. Soulie et al., "Cord blood T lymphocytes lack constitutive perforin expression in contrast to adult peripheral blood T lymphocytes," Blood, vol. 85, no. 6, pp. 1540-1546, 1995.

[25] R. Agarwal, A. Loganath, A. C. Roy, Y. C. Wong, and S. C. $\mathrm{Ng}$, "Expression profiles of interleukin-15 in early and late gestational human placenta and in pre-eclamptic placenta," Molecular Human Reproduction, vol. 7, no. 1, pp. 97-101, 2001.

[26] S. B. Sable, S. Kaur, I. Verma, and G. K. Khuller, "Immunodominance of low molecular weight secretory polypeptides of Mycobacterium tuberculosis to induce cytotoxic Tlymphocyte response," Vaccine, vol. 23, no. 41, pp. 4947-4954, 2005.

[27] M. Santosuosso, X. Zhang, S. McCormick, J. Wang, M. Hitt, and Z. Xing, "Mechanisms of mucosal and parenteral tuberculosis vaccinations: adenoviral-based mucosal immunization preferentially elicits sustained accumulation of immune protective CD4 and CD8 T cells within the airway lumen," Journal of Immunology, vol. 174, no. 12, pp. 7986-7994, 2005.

[28] S. Cho, V. Mehra, S. Thoma-Uszynski et al., "Antimicrobial activity of MHC class I-restricted $\mathrm{CD}^{+} \mathrm{T}$ cells in human tuberculosis," Proceedings of the National Academy of Sciences 
of the United States of America, vol. 97, no. 22, pp. 12210 $12215,2000$.

[29] G. D. Hussey, M. L. V. Watkins, E. A. Goddard et al., "Neonatal mycobacterial specific cytotoxic T-lymphocyte and cytokine profiles in response to distinct BCG vaccination strategies," Immunology, vol. 105, no. 3, pp. 314-324, 2002.

[30] P. Wolint, M. R. Betts, R. A. Koup, and A. Oxenius, "Immediate cytotoxicity but not degranulation distinguishes effector and memory subsets of CD8 ${ }^{+}$T cells," Journal of Experimental Medicine, vol. 199, no. 7, pp. 925-936, 2004.

[31] R. A. Murray, N. Mansoor, R. Harbacheuski et al., "Bacillus Calmette Guerin vaccination of human newborns induces a specific, functional CD8+ T cell response," Journal of Immunology, vol. 177, no. 8, pp. 5647-5651, 2006.

[32] C. F. Capinos Scherer, J. J. Endsley, J. B. De Aguiar et al., "Evaluation of granulysin and perforin as candidate biomarkers for protection following vaccination with mycobacterium bovis BCG or M. bovis $\triangle \mathrm{RD} 1$," Transboundary and Emerging Diseases, vol. 56, no. 6-7, pp. 228-239, 2009.

[33] L. Maródi, "Innate cellular immune responses in newborns," Clinical Immunology, vol. 118, no. 2-3, pp. 137-144, 2006.

[34] M. L. V. Watkins, P. L. Semple, B. Abel, W. A. Hanekom, G. Kaplan, and S. R. Ress, "Exposure of cord blood to Mycobacterium bovis BCG induces an innate response but not a T-cell cytokine response," Clinical and Vaccine Immunology, vol. 15, no. 11, pp. 1666-1673, 2008.

[35] G. P. White, P. M. Watt, B. J. Holt, and P. G. Holt, "Differential patterns of methylation of the IFN- $\gamma$ promoter at $\mathrm{CpG}$ and non-CpG sites underlie differences in IFN- $\gamma$ gene expression between human neonatal and adult CD45RO- T cells," Journal of Immunology, vol. 168, no. 6, pp. 2820-2827, 2002.

[36] J. J. Endsley, M. A. Endsley, and D. Mark Estes, "Bovine natural killer cells acquire cytotoxic/effector activity following activation with IL-12/15 and reduce Mycobacterium bovis BCG in infected macrophages," Journal of Leukocyte Biology, vol. 79, no. 1, pp. 71-79, 2006.

[37] F. Dieli, G. Sireci, N. Caccamo et al., "Selective depression of interferon- $\gamma$ and granulysin production with increase of proliferative response by $\mathrm{V} \gamma 9 / \mathrm{V} \delta 2 \mathrm{~T}$ cells in children with tuberculosis," Journal of Infectious Diseases, vol. 186, no. 12, pp. 1835-1839, 2002.

[38] E. Sahiratmadja, B. Alisjahbana, S. Buccheri et al., "Plasma granulysin levels and cellular interferon- $\gamma$ production correlate with curative host responses in tuberculosis, while plasma interferon- $\gamma$ levels correlate with tuberculosis disease activity in adults," Tuberculosis, vol. 87, no. 4, pp. 312-321, 2007.

[39] A. Van Rie, S. A. Madhi, J. R. Heera et al., "Gamma interferon production in response to Mycobacterium bovis BCG and Mycobacterium tuberculosis antigens in infants born to human immunodeficiency virus-infected mothers," Clinical and Vaccine Immunology, vol. 13, no. 2, pp. 246-252, 2006.

[40] J. J. Endsley, A. Hogg, L. J. Shell et al., "Mycobacterium bovis BCG vaccination induces memory CD4+ T cells characterized by effector biomarker expression and anti-mycobacterial activity," Vaccine, vol. 25, no. 50, pp. 8384-8394, 2007.

[41] C. F. Zheng, L. L. Ma, G. J. Jones et al., "Cytotoxic CD4 ${ }^{+}$T cells use granulysin to kill Cryptococcus neoformans, and activation of this pathway is defective in HIV patients," Blood, vol. 109, no. 5, pp. 2049-2057, 2007.

[42] M.-T. Ochoa, S. Stenger, P. A. Sieling et al., "T-cell release of granulysin contributes to host defense in leprosy," Nature Medicine, vol. 7, no. 2, pp. 174-179, 2001.

[43] J. Andersson, A. Samarina, J. Fink, S. Rahman, and S. Grundström, "Impaired expression of perforin and granulysin in CD8+ T cells at the site of infection in human chronic pulmonary tuberculosis," Infection and Immunity, vol. 75, no. 11, pp. 5210-5222, 2007.

[44] Y. Tsunetsugu-Yokota, H. Tamura, M. Tachibana, K. Ogata, M. Honda, and T. Takemori, "Selective expansion of perforinpositive CD8+ T cells by immature dendritic cells infected with live Bacillus Calmette-Guérin mycobacteria," Journal of Leukocyte Biology, vol. 72, no. 1, pp. 115-124, 2002.

[45] L. L. Ma, J. C. L. Spurrell, J. F. Wang et al., "CD8 T cell-mediated killing of Cryptococcus neoformans requires granulysin and is dependent on CD4 T cells and IL-15," Journal of Immunology, vol. 169, no. 10, pp. 5787-5795, 2002.

[46] W. J. Leonard and R. Spolski, "Interleukin-21: a modulator of lymphoid proliferation, apoptosis and differentiation," Nature Reviews Immunology, vol. 5, no. 9, pp. 688-698, 2005.

[47] G. A. W. Rook, D. B. Lowrie, and R. Hernández-Pando, "Immunotherapeutics for tuberculosis in experimental animals: is there a common pathway activated by effective protocols?" Journal of Infectious Diseases, vol. 196, no. 2, pp. 191-198, 2007.

[48] A. Marchant, T. Goetghebuer, M. O. Ota et al., "Newborns develop a Th1-type immune response to Mycobacterium bovis bacillus Calmette-Guerin vaccination," Journal of Immunology, vol. 163, no. 4, pp. 2249-2255, 1999.

[49] T. M. Doherty and G. Rook, "Progress and hindrances in tuberculosis vaccine development," The Lancet, vol. 367, no. 9514, pp. 947-949, 2006.

[50] G. A. W. Rook, R. Hernandez-Pando, K. Dheda, and G. Teng Seah, "IL-4 in tuberculosis: implications for vaccine design," Trends in Immunology, vol. 25, no. 9, pp. 483-488, 2004.

[51] J. D. Ahlers and I. M. Belyakov, "Memories that last forever: strategies for optimizing vaccine T-cell memory," Blood, vol. 115, no. 9, pp. 1678-1689, 2010.

[52] J. A. C. Sterne, L. C. Rodrigues, and I. N. Guedes, "Does the efficacy of BCG decline with time since vaccination?" International Journal of Tuberculosis and Lung Disease, vol. 2, no. 3, pp. 200-207, 1998.

[53] M. A. Behr, "Correlation between BCG genomics and protective efficacy," Scandinavian Journal of Infectious Diseases, vol. 33, no. 4, pp. 249-252, 2001. 


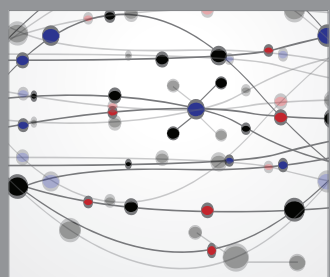

The Scientific World Journal
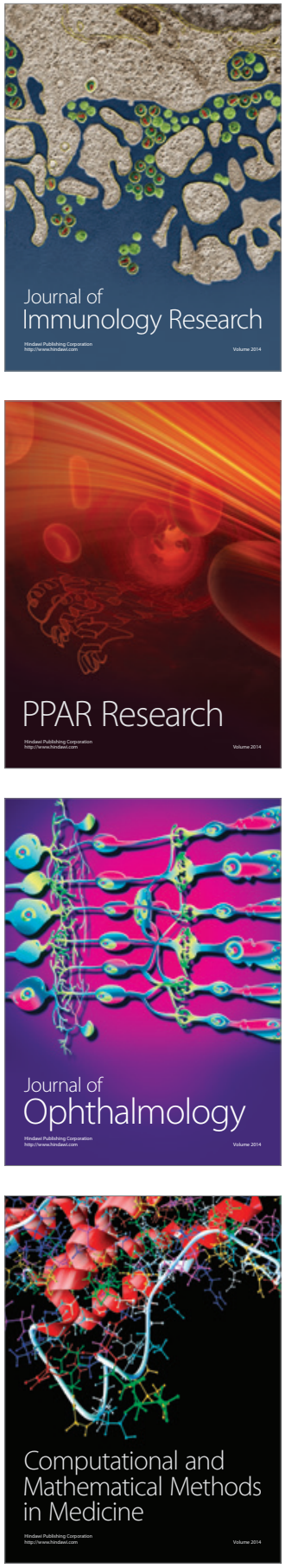

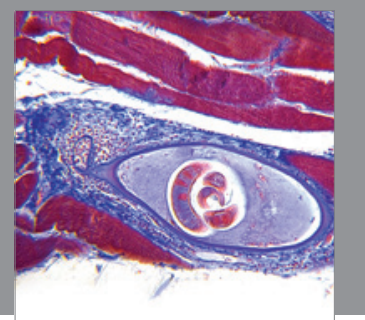

Gastroenterology

Research and Practice
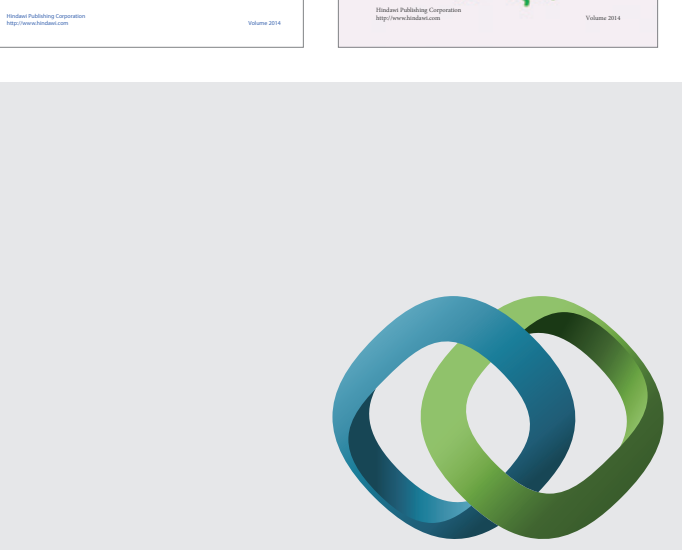

\section{Hindawi}

Submit your manuscripts at

http://www.hindawi.com
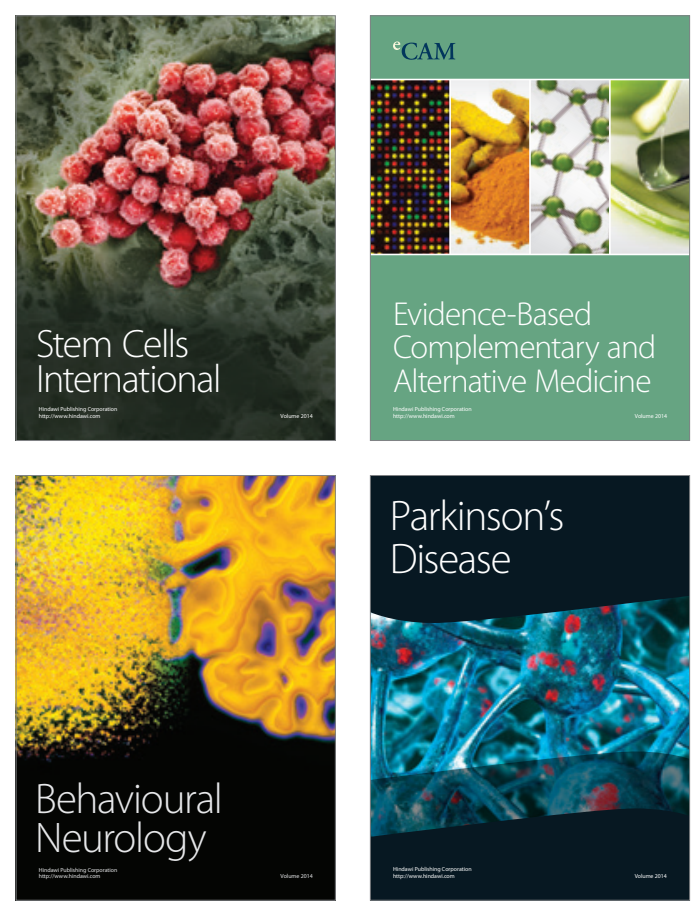

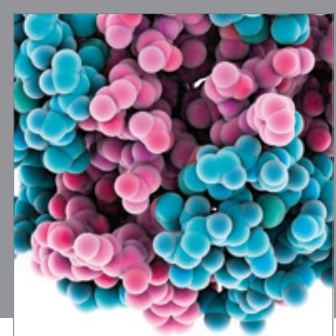

Journal of
Diabetes Research

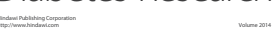

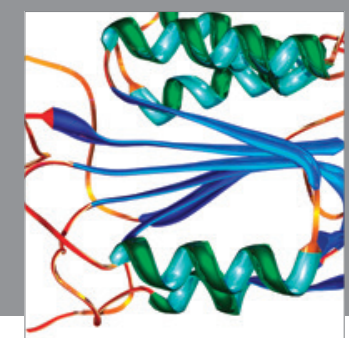

Disease Markers
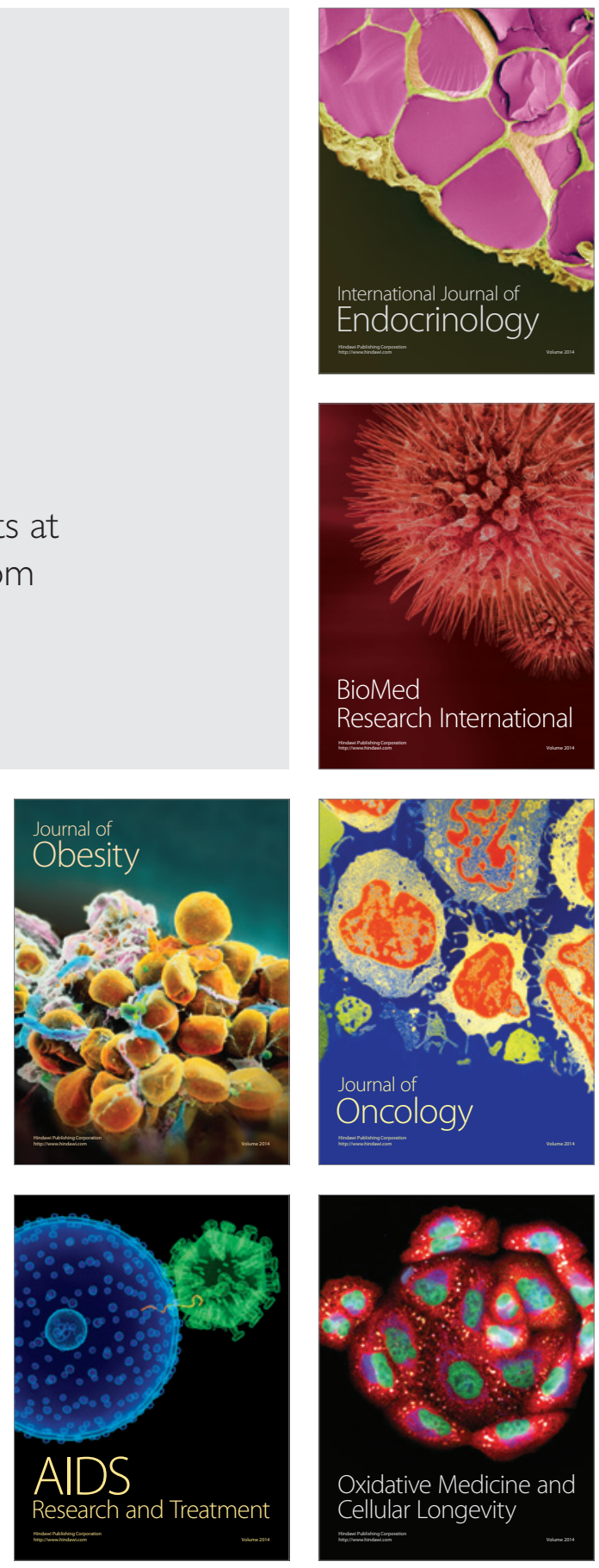